Stephen R. Grimm, Fordham University

Forthcoming: The Routledge Companion to Virtue Epistemology, Ed. Heather Battaly

Draft: 8-1-17

\title{
UNDERSTANDING AS AN INTELLECTUAL VIRTUE
}

Since the publication of Linda Zagzebski's groundbreaking Virtues of the Mind in 1996, virtue epistemologists have been notable for focusing not just on the epistemic good of knowledge, but also on the so-called "higher" epistemic goods of understanding and wisdom. ${ }^{1}$ The shared idea seems to be that if we think of an intellectual virtue in the way Zagzebski suggested-as an "excellence of the mind" - then there is something one-sided about focusing only on excellences such as knowledge. Instead, our epistemology should be broad enough to encompass the full range of intellectual excellences we care about, understanding and wisdom included.

In this chapter I will focus on one of these higher goods in particular, the good of understanding, and I will consider the various ways in which it can be thought of as an excellence of the mind. More exactly, I will try to clarify both the nature of understanding considered as an epistemic goal or accomplishment (the intellectual excellence sought), as well as explore the distinctive powers of the mind or character traits that are needed to realize this accomplishment. ${ }^{2}$

In addition, I will take up the question of whether there is something importantly different, from an epistemic point of view, about the sort of understanding we

\footnotetext{
${ }^{1}$ For work from virtue epistemologists on understanding or wisdom, see for example Zagzebski (1996; 2001; forthcoming), Sosa (2001; forthcoming), Riggs (2003), Roberts and Wood (2007), Pritchard (2010), Greco (2014; 2016), Baehr (2014; forthcoming), Grimm (2015), and Battaly (2015: ch. 2). Note that by "knowledge" here I mean "propositional knowledge"; later I will consider more expansive understandings of the term.

2 The notion of an "excellence of the mind" is therefore act/object or process/product ambiguous in the same way that notions such as "belief" and "explanation" are. Thus on the one hand, an "excellence of the mind" might refer to the epistemic product or accomplishment sought: for instance, to "excellences of the mind" such as knowledge or wisdom or understanding. This seems to have been how Aristotle conceived of intellectual virtues. Thus in enumerating the intellectual virtues in Book VI of the Nicomahean Ethics, he listed accomplishments such as sophia (theoretical wisdom), episteme (understanding), nous (rational insight), and phronesis (practical wisdom). On the other hand, it might refer to the properties, faculties, or traits of the person that help us to achieve these epistemic ends. This is mainly the way in which contemporary epistemologists have thought of the notion of an intellectual virtue, with differences arising as to how to think about those traits-whether in terms of "character-level" intellectual traits such as open-mindedness or intellectual courage, or in terms of "faculty-level" traits such as good eyesight or excellent memory. For excellent overviews see Baehr (2011: ch. 1) and Battaly (2015).
} 
have of people (as when we understand why our friend is upset), as opposed to the sort of understanding we have of the natural world (as when we understand why the tides are high rather than low). For instance, does understanding other people require us to bring other powers of the mind to bear, or to exercise more "character-level" virtues than we find in our understanding of the natural world?

For the most part my goal in this chapter will simply be to clarify the terrain, and to elucidate the various ways in which understanding can be seen as an excellence of the mind or intellectual virtue. But I will also have occasion to enter into some ongoing debates, and to try to introduce some new questions into the literature. In terms of ongoing debates, I will side with Jason Baehr in his recent dispute with Ernest Sosa, by defending Baehr's claim that "characterlevel virtues" - things like open-mindedness or intellectual courage, as opposed to "faculty-level virtues," such as good eyesight or good memory-can be constitutively involved in acquiring certain epistemic goods, and in particular the good of understanding. I will also say more on behalf of a controversial claim I have defended elsewhere-that understanding deserves to be thought of as a kind or species of knowledge.

In terms of introducing new questions, I will take up the neglected issue of what it might mean to be an "understanding person" - by which I mean not a person who understands a number of things about the natural world, but a person who steers clear of things like judgmentalism in her evaluation of other people, and thus is better able to take up different perspectives and view them with a sympathetic eye. Being an understanding person in this sense seems to be a character-level virtue that interestingly combines moral and epistemic elements; it also seems to be a virtue particularly needed in our age of deep political division, where it is commonly said that failures of understanding are partly to blame for this division ("I can't understand why anyone would even think about voting for Trump/Brexit, etc.)," or "I can't understand how anyone could support the idea that Black Lives Matter. Don't all lives matter?").

More mutual understanding seems needed in all these areas, and perhaps a small step in this direction can be taken by clarifying what it might mean to be an understanding person in the first place. That is the main issue I will address in the concluding sections of this chapter.

\section{Understanding the Natural World}

First, what does it take to understand the natural world? A common thought is that in order to understand the world-or, more likely, some portion of it-we need to see how its various elements "hang together." On this view the objects of understanding appear to be systems or networks of some kind, and understand involves grasping how these things "work" - that is, how the 
different elements of the system or network depend upon and relate to one another. ${ }^{3}$

This contrasts with the objects of knowledge, which might be more isolated or atomistic. Thus you might know that Trenton is the capital of New Jersey, or that you had eggs on toast for breakfast this morning, but it would sound odd to say you understand these things. ${ }^{4}$ It is also not obvious that if you bundled several items of knowledge together-at least, items of propositional knowledge-that this would magically yield understanding. Thus you might know a lot about the sport of cricket, or about helicopters, without really understanding cricket or helicopters. Understanding thus seems to require not just holding several related things before the mind, but in some way "seeing" or "grasping" or appreciating this relatedness.

Consider an example. Suppose a child-say, an eight year old-for the first time sees someone fill a balloon with helium and release it, so that the balloon rises into the air. The child will, I take it, be suitably amazed. What is going on!? Why didn't the balloon just drop straight to the ground when the man let it go? The child's desire to understand will naturally be piqued.

Suppose the child then tries to figure out why the balloon rose. She might wonder, for instance, whether it was the color of the balloon that made a difference to the rising, or the time of day when it was released, or where it was released, or who released it. Suppose however that through further observation she comes to believe that it was none of these things. Instead, she concludes that it was the presence of this mysterious gas - the "helium" - that made the difference.

She will then, I take it, have some degree of understanding of why the balloon rose, and this is because she will have grasped a real relation of dependence that obtained in the world, and distinguished it from other possible but spurious relations. Gaining insight into this network of real and merely possible relationships will also allow her to answer a range of what James Woodward (2003) has called "What if things had been different?" questions. For instance, in identifying the real relation and ruling out the spurious ones, she will be able to infer that changing things like the color of the balloon, or the time of day it was

\footnotetext{
${ }^{3}$ As Julius Moravcsik puts the idea, which he finds in Plato and other ancient thinkers, "What we understand are systems of various sorts; in a world in which elements do not constitute the relevant structures there can be no understanding" (Moravcsik 1979: 56).

4 Except as a kind of "hedging" use of "understands," where you want to indicate a less-thancomplete endorsement of the claim in question. See Elgin (2007) and Grimm (2011).
} 
released, will not make a difference to the rising or falling. ${ }^{5}$ On the other hand, she will likely believe that changing the contents of the balloon (from helium to something else), or leaving it uninflated altogether, will make a difference.

As we might put it, someone who grasps these things will therefore have command of the "modal space" around the focal event. He or she will appreciate how changing the value of some variables will lead to changes in the focal event, while changing the value of other variables will not.

Two further points on this general idea. First, a natural way to think about growth in understanding, on this model, is that it will involve an even greater command of the relevant modal space. Thus identifying the helium as the cause of the rising is presumably only the beginning of the story, and as someone grows in understanding he or she will be able to identify what it is about the helium that leads balloons filled with it to rise rather than fall.

For instance, once someone learns that helium-filled balloons rise rather than fall because helium is lighter than the ambient air in the Earth's atmosphere, he will be able to infer that a balloon filled with any other gas lighter than air will also rise. For instance, he will be able to infer, in tandem with some additional information from the periodic table, that if the balloon were filled with hydrogen rather than helium, it would also rise. Deeper understanding therefore goes hand in hand with an appreciation of the deeper variables and relationships that underlie the world, and this in turn is tied to a greater cognitive command over the relevant modal space. ${ }^{6}$

A second point is that this general picture of understanding-where relationships or dependencies are the things that are grasped, and where grasping these relationships or dependencies allows us to appreciate how the system in question "works" - plausibly brings distinctive powers of the mind to bear, and thus serves to mark it as a distinctive excellence of the mind.

For comparison, take a simple case of perceptual knowledge-say, one where I know that there is a stapler on my desk. Here it seems fair to say that the power of the mind at work is vision, a capacity that allows me to take in how things are in my immediate environment. Or again, consider my knowledge that I had eggs on toast for breakfast this morning. Here I take it the power of the mind

\footnotetext{
${ }^{5}$ Ceteris paribus, and not taking into account eccentric cases where changing (say) the color triggers other consequences. I will stop repeating the "ceteris paribus" clause in the remainder of this section, but it should be understood.

${ }^{6}$ This idea of "cognitive command" is obviously similar to, but I believe distinct from, Alison Hills's important idea of "cognitive control" (see Hills 2016). From private conversation, I don't believe Hills would endorse the Woodward-based account I am defending here.
} 
involved is memory. And so on with other examples involving distinctive powers of the mind, such as introspection or rational inference.

I suggest that understanding too brings a distinctive power of the mind to bear because it is concerned not simply with how things actually are or were (the provinces of perception and memory), but also and I think more crucially with how they might be-in other words, with what things are capable of, and with how they will react in the face of certain inputs from the world, or changes in the environment. This is what it means, I suggest, to have control of the modal space surrounding the thing we want to understand.

Now, in light of this brief sketch, epistemologists might naturally wonder whether appealing to this allegedly "new" or distinct power of the mind, tied in this way to modal control, implies that we have something quite different than knowledge on our hands. Put another way, it might be wondered whether this account implies that the sort of understanding the eight-year old has with respect to the balloon is not a species of knowledge. ${ }^{7}$

I do not think there is any such implication here, however. Consider, for instance, that we are already comfortable with the idea that items of a priori knowledge-to state the obvious-count as knowledge. And yet here we seem to have a very distinctive power of the mind at work: the power to take in not just how things are, or how they might be, but apparently how they must be. For instance, not just that $7+5$ happens to equal 12 , but that it must equal 12 , or that there is no possible world in which it fails to equal $12 .^{8}$ We are willing to count mental states such as this as items of knowledge, it seems, just in case they get things right in a reliable way, and not just by accident.

Assuming, as seems fair, that different powers of the mind can forge this reliable connection, then they too would count as sources of knowledge. Knowledge thus seems more like a house with many rooms than like a narrow silo-a house that allows space for perceptual knowledge, a priori knowledge, the sort of knowledge involved in having cognitive control of modal space (i.e., understanding, if what we have said is correct), and more besides.

\section{Intellectual Character and Understanding}

With this brief review of the cognitive abilities or powers that seem especially important for understanding the natural world in mind, we can now ask: Are there any character-level intellectual virtues that seem especially important for

\footnotetext{
${ }^{7}$ For more on the issue of whether understanding is a species of knowledge, see e.g. Kvanvig (2003), Grimm (2006), Sliwa (2015), Hills (2016), and Lawler (2016).

${ }^{8}$ For more on the comparison with understanding and a priori knowledge, see Grimm (2014).
} 
this type of understanding? Perhaps goods such as open-mindedness, or intellectual inquisitiveness, or intellectual creativity?

It might be thought that all of these character traits, and more besides, are especially important for understanding, because understanding seems to be notably harder to acquire than knowledge-as Duncan Pritchard (2010) has argued, it seems much more clearly an epistemic achievement than knowledge. Thus I can know, more or less automatically, that the stapler is on my desk, but the sort of achievement involved in identifying helium as the cause of the rising of the balloon involved some degree of figuring things out. Thus the eight-year old above needed to rule out some hypotheses and entertain others, a process that undoubtedly involved factors such as attentiveness, creativity, and an openness to her own fallibility.

Along the same lines, it might seem that understanding is a process that stretches out over time and involves inquiry, hence that character-level virtues are important for keeping this inquiry on track in a way that they are not necessarily important for keeping other, more instant and automatic, epistemic accomplishments on track. As Jason Baehr has noted, it hardly takes traits such as open-mindedness and inquisitiveness in order to appreciate that the lights in the room have suddenly gone out (Baehr 2011: 44). We can, it seems, know this sort of thing automatically, just so long as our brute perceptual hardware is functioning properly. Strictly speaking, knowledge therefore does not require character-level traits for its realization, but understanding-given the obstacles we often face in acquiring it-perhaps does.

And yet, it is important to note that there are simple cases of understanding that seem to be just as automatic - just as much a function of brute proper function-as we see in Baehr's case of knowing that the lights just went out. Suppose you are sitting at a table next to me in a coffee shop, and you notice that as I try to stand I jostle the table with my knee. The table then wobbles and some of the coffee in my cup spills. If your basic cognitive equipment is functioning properly, you will automatically take the jostling to be the cause of the table's wobbling, and the wobbling to be the cause of the spill. You will likewise more or less automatically rule out the music on the radio as the cause of the spill, or the fact that it is currently raining outside. In a flash you will therefore correctly identify the "real dependencies" that obtain in the worldconnecting the spill to the wobbling, the wobbling to the jostling, and so on.

In a good number of our everyday, taken-for-granted interactions with the world, traits like open-mindedness, conscientiousness, and so on therefore do not seem to play much of a role in the acquisition of understanding, if they play any role at all. We seem instead to be hardwired to pick out a fairly wide range of dependencies. There also seem to be no obvious intellectual vices that need 
to be overcome in cases like this (close-mindedness? intellectual timidity?), and hence that would require the assistance of the virtues. The brute processing does the work for us, it seems.

\section{Understanding People}

So far I have focused on what is involved in understanding things like natural events or natural systems, and I have tried to characterize both (a) the intellectual powers or excellences that yield this sort of understanding, as well as (b) the character-level intellectual traits that appear to be sometimes, but apparently not across-the-board, involved in its realization.

There is a long tradition of thought, however, according to which understanding human beings requires a different set of powers or capacities-hence a different set of intellectual virtues - than we find when it comes to understanding the natural world. ${ }^{9}$ We should therefore ask whether there are any intellectual traits, including character-level traits, that might be more intimately involved with understanding people than with understanding the natural world.

For simplicity, I will focus for the moment on the complex trait of being "an understanding person." That is to say, the trait that we attribute to someone when we say things like: "You should go talk to Rachael about this-she is a very understanding person." Or, alternatively, it is a trait that we deny of someone when we say: "You know, Dan, you are much too quick to judge your daughter. You should try to have more understanding of what she is going through." I say the trait is complex, because it seems to tie together epistemic and moral considerations on the one hand, and person-level and faculty-level intellectual considerations on the other hand, in a way that we find in few if any other character traits.

To get a better sense of what I have in mind, consider the following passage from the Cambridge classicist Mary Beard, taken from her 2016 BBC television series on Ancient Rome. Beard speaks these words to the camera as she strolls through the ruins of the ancient Greek city of Ephesus, which was one of the main slave trading centers of the Roman world.

"Slaves flowed through the marketplace at Ephesus like olive oil through Seville. The brutal truth was, many Romans would not have seen much of a distinction between the two. As they saw it, slaves were one of the

\footnotetext{
${ }^{9}$ This is the view associated with thinkers such as Giambattista Vico, Wilhelm Dilthey, and R.G. Collingwood. For contemporary appraisals of this approach, see Stueber (2012) and Grimm (2016).
} 
products of Empire: many were victims of Roman conquests, or kidnappings, or just foundlings.

[Beard continues to walk through the ruins.] If you wanted to buy a slave, this is where you would have come. It's uncomfortable to grasp, but the Roman Empire depended on slave labor, and like every other ancient society, the Romans took slave labor absolutely for granted.

But uncomfortable as it is, if we want to understand rather than just deplore what went on here, we have to try to get into the mindset of those who came to buy slaves. What did they think they were doing? My guess is: they thought they were doing their shopping. Perhaps they were here after a gardener, or a tutor for their child, or maybe a hairdresser. How were they going to be sure they weren't ripped off? Could they trade in last year's model? And were they missing out on a special offer next week: three for two?

That may seem a very callous way of putting it, but it was the everyday reality of Roman life." (Beard 2016)

There are a number of interesting things going on in this passage. For one thing, there is the idea that to understand another culture you need to try to "get into" that culture's mindset-with the implication that this act of getting into an alternative mindset might require a particular mental ability or skill, perhaps along the lines of empathy. As importantly for our purposes, however, there is the claim that getting into the mindset of an unfamiliar culture often requires us to overcome our feelings of moral condemnation or moral superiority-it requires, in Beard's insightful words, that we try "to understand rather than just to deplore."

Although I believe both of these elements-concerning (a) the distinctive mental act of getting into the mindset of others, and (b) the character-level virtues that help us to steer clear of what we might call "judgmentalism"-are important for understanding others, I will take up the question of what it might mean to steer clear of judgmentalism first. I will then turn to the question of what it might mean to enter the mindset of another culture, or perhaps just someone from our own culture who is quite different than us.

\section{Judgmentalism and Understanding}

Judgmentalism seems to be a vice with both an epistemic and a moral aspect. ${ }^{10}$ Epistemically speaking, it looks like a vice because it leads us to form false beliefs

${ }^{10}$ For a very helpful overview, see Simon (1989). 
about the motives and character traits of others. It is easy to suppose, for instance, that the Romans who embraced slavery were simply wicked or hateful, or in various ways heedless of the suffering of others. But what if instead-and more plausibly - their attitude towards their slaves was more complex and subtle than that? For instance, what if the Romans felt their slaves had simply gotten the bad end of an apparently timeless arrangement, one according to which the losers in wars of aggression became slaves as a result of bad luck-the sort of bad luck that might, some day, afflict the Romans themselves? In that case, as Beard suggests, getting inside the mind of a Roman would not involve getting inside the mind of a sadist, or one indifferent to the suffering of others. A slave's "owner" might well regret the suffering, but see it as part of this arrangement that, in some sense, everyone implicitly accepted.

Being too quick to deplore, rather than working to understand, will therefore have a range of epistemic drawbacks. For one thing, it will lead us to misportray the psychological profiles and moral standing of others, because it will make us too quick to attribute wicked or malicious motives, rather than more ordinary motives, and more ordinary faults, such as excessive cultural conformism, or simple selfishness, or intellectual laziness. ${ }^{11}$ For another, being too quick to deplore encourages us to misportray our own moral standing, for it is hard not to condemn the wickedness and malice of others without subconsciously patting ourselves on the back, thinking "Well, I may have my faults, but at least I am not that bad." Or perhaps: "At least I would never do a thing like that." This is a further epistemic fault, because all of these evaluative claims about ourselves, as things like the Milgram experiments and Stanford Prison Experiments show, might well be false.

What is more, these epistemic drawbacks of judgmentalism will likely exist sideby-side with traditionally "moral" faults too, such as excessive self-satisfaction and arrogance-an inability to appreciate one's own moral frailty, or how true it is that "there but for the grace of God go I." Actually, the expression "side-byside" is almost certainly too weak here, because the epistemic and moral faults in cases of judgmentalism will be so deeply intertwined. Thus a desire to think ourselves exceptional leads us to misportray the psychological profiles of others,

\footnotetext{
${ }^{11}$ For comparison, and to bring the point closer to home: suppose, two hundred years from now, it becomes eminently, unquestionably clear that eating meat is deeply wrong - that the suffering endured by non-human animals is in fact far greater than anyone ever suspected in 2017, and that the most widely accepted theories of rights in 2217 clearly extend to animals. The people in 2217 then trying to understand, rather than just deplore, what it was like to be a meat eater in 2017 would do well to attribute the moral error not to malice or sadism, but rather again to the ordinary range or moral failings, including excessive conformism, selfishness, laziness, and so on. That is not to say, I stress, that we would not be morally to blame or morally at fault. It would just be a kind of fault where wickedness or malice was not the primary explainer.
} 
which leads to a misplaced sense of moral self-satisfaction or righteousness, which makes us more apt to misportray in the future... and so on.

In short, if the vice of judgmentalism leads us to say things like, "They knew this was evil, and yet, because of their corrupt character, they opted to do it anyway," the epistemic virtue of understanding should lead us to ask things like: "Under what aspect of the good were they acting?" or "Why did this seem like the best thing to do under these circumstances?" or "How easy was it to know how to behave well in this situation?" What's more, if judgmentalism encourages us, as a default, to attribute poor behavior to a person's deficient character, the virtue of understanding encourages us to look for other circumstances that might be responsible instead-an illness perhaps, or a difficult patch in a person's life, or some non-culpable ignorance, or some cultural presupposition that only a super-human could have dislodged, and so on.

This is not to say, I should stress, that character-level faults are never the main source of wrong-doing, or that a person with understanding will never conclude that they are. ${ }^{12}$ It is just to say that the virtue of understanding will-among other things-bid someone to look for extenuating factors that might be in the picture, rather than assume that a character-level fault is to blame.

Thinking in terms of an Aristotelian mean, we might say that with respect to portraying and evaluating the psychological profiles of others, we have the following spectrum:

Excess Mean Deficiency

Judgmental ---- Understanding ---- Naïve/Pollyannaish/Overly permissive

We have spoken mainly of the first two categories so far, but I hope this has put us in a better position to appreciate the third category listed here-one that is difficult to label aptly, but should be familiar enough. This relates to a person who resists ascriptions of individual blame altogether, even where those ascriptions would be correct-where the tendency is always and unfailingly to find fault with the situations or circumstances, rather than with the person. Here again, we have an interesting mix of epistemic and moral vice, it seems: epistemic, because it leads to false beliefs about blameworthiness; but also moral, because it perhaps shows an insufficient regard for justice or personal responsibility or human autonomy.

In any case, the basic idea is that an understanding person will not be naïve or a moral pushover. He or she will charitably try to interpret the motives and

\footnotetext{
12 I make this case more fully in Grimm (forthcoming).
} 
circumstances of others, while realizing that human beings often fall short of what justice requires.

\section{Constitutive or Auxiliary?}

This person-level virtue of understanding-or, more naturally in English, of being an understanding person-therefore helps us to portray accurately the psychological profiles and moral standing of others. But now we can ask, in light of one of the most interesting ongoing debates in the literature: In what way does it help? Does it help, as Ernest Sosa has suggested with respect to other character virtues, in an "auxiliary" way-in the sense that it helps position us correctly with respect to acquiring the truth, even though it doesn't actually help in acquiring the truth itself? ${ }^{13}$ Alternatively, as Jason Baehr has argued, does it help in a more "constitutive" way-that is, is the character virtue somehow ingredient in the understanding itself, rather than a mere prelude to it? ${ }^{14}$

As I have described the trait of being an understanding person, I think the evidence favors a constitutive reading. In particular, being understanding helps to steer us away from the natural tendency many of us have to deplore the behavior of others, or to be judgmental. It thus corrects for this natural bias.

For comparison, imagine an archer who aims for the bullseye with the aid of an advanced bow that helps to reduce the tremors and shaking he usually feels as he draws back the bow string. Suppose he then hits his target. Why did he do so? There will undoubtedly be a number of important factors at play here, including the excellent eyesight that allowed him to aim properly, the physical strength that helped him to pull back the bowstring, and the know-how that allowed him to pull the string back just this far and no further. Clearly, however, as I have described the case the tremor-dampening properties of the bow will also have played a crucial role, for without them, we can suppose, the arrow would have veered well off course.

Now suppose that over time the archer, as it were, "interiorizes" the tremordampening properties of the bow, so that he is able to still himself without the help of the equipment. In that case it seems entirely plausible that his interior competence to hit the target will be partly constituted by this trait. More precisely, it will be this trait that will enable him to harness his other powershis good eyesight, his strength, and his know-how-and direct them in the right way.

\footnotetext{
${ }^{13}$ See Sosa (2015: ch. 2). Compare: drinking a strong cup of coffee while driving might help you to see properly in an auxiliary way, in the sense that it helps you to keep your eyes open and alert. Knowing that there is a squirrel scampering across the road will be almost entirely a function of your good eyesight, not the coffee.

${ }^{14}$ See especially Baehr (2011: Ch. 4; 2016).
} 
I hope the analogy is clear. When our tendency is towards judgmentalism, we need the virtue of understanding to steer us away from this vice in our attempts to characterize the psychological profiles and moral statuses of others. Even when someone might have successfully "interiorized" this virtue, moreover, so that he or she no longer needs to fight against the inclination to be judgmental, it will still plausibly be playing a regulative and constitutive role in achieving the truth. As Alvin Goldman has noted, "it is a psychological commonplace that highly developed skills become automatized" (Goldman 1989: 190)-in other words, that they eventually do their guiding, harnessing, and regulative work below the level of conscious choice or awareness. This does not imply either that they are not active, or that they should no longer be considered characterlevel traits. Instead, they are character-level traits that have become so deeply embedded in who someone is that they help to constitute the person's competence to find the truth in these areas.

\section{Understanding and Perspective-Taking}

Turning to conclude, let us take up one last issue. For suppose you have the virtue of being an "understanding person" as just described-that is, the sort of person who among other things does not blame or find fault too hastily or severely, on the one hand, or never at all, on the other hand. How do you move from that state to being someone who actually understands another person?

I grant this question might sound odd, but this is again because of the ambiguity we noted earlier in the notion of "understanding."15 On the one hand, it might refer to the character trait just described-a disposition not to blame or deplore too hastily, etc. On the other hand, it might refer to the epistemic accomplishment sought-the good of understanding others, which the character-level virtue of being an understanding person helps one to achieve. With this distinction in mind, we can now turn our attention specifically to the epistemic end sought - the good of understanding other people-and ask in particular how understanding other people might differ from understanding the natural world.

Recall that according to our earlier framework understanding was a matter of grasping how something "worked." With respect to the natural world, this amounted to grasping how the various elements of the world depended upon and related to one another. It meant apprehending that whether a balloon rose or fell, for instance, depended upon the mass of the materials inside the balloon, and whether this was greater or lesser than the surrounding atmosphere.

\footnotetext{
${ }^{15}$ An ambiguity it inherits, as I noted in footnote 2, from the ambiguity found in the "excellence of the mind" idea itself.
} 
Perhaps, then, we can simply take over this model whole-cloth and apply it to our understanding of other people. After all, human minds are also systems of a sort, in which different elements-beliefs, desires, loves, fears, and so on-relate to and depend upon one another in various ways. We might therefore imagine a traveler from a very different species, perhaps from a remote corner of the universe, studying a human being and coming to appreciate how a person's mind "worked"-hence understanding, in a sense, why the person acted in this way rather than otherwise (because, perhaps, of these beliefs and desires rather than some other).

But while the traveler would then understand, I take, at least something about human beings - something about the relationships among the person's beliefs, actions, and desires, for instance-it also seems possible, and perhaps likely, that something else would be lost. It would not be difficult to imagine the human being complaining, for instance, that the traveler wouldn't "really" understand him at all, if all the traveler grasped were these systematic dependencies. What then would be missing? What is it that the traveler would fail to appreciate or apprehend?

One particularly salient thing the traveler would fail to understand, I suggest, is what it's like to be human-something that arguably no amount of studying a human being from an objectivizing, third-person perspective, could shed light on. Some care is needed to unpack this thought, however, because the notion of "what it's like" can be taken in a number of different ways, some of which are less significant for our purposes here.

First, there is what we might call a phenomenal sense of what it's like, which emphasizes the qualitative or felt dimension of a state. ${ }^{16}$ This is the sense in which there is something that it's distinctively like to see crimson, or to taste vanilla ice cream, or to smell cooking garlic. This is also the sense of "what it's like" that has received the most attention in the literature, in response to Thomas Nagel's famous essay on the subject (Nagel 1974). There is another sense of "what it's like," however, that I believe is even more fundamental to the project of understanding others: what we might call the attitudinal sense of "what it's like." To grasp "what it's like" in this sense is to be able to successfully "take up" the person's attitudes, and thus to be able to imagine what it would be like to care about things in the way the other person does, or to have the same sorts of worries, hopes, and concerns the agent does.

Understanding others in this sense seems to require a number of different mental abilities. For one thing, it plausibly involves the ability to mentally

\footnotetext{
${ }^{16}$ For more on phenomenal understanding, see Lilian O'Brien (forthcoming).
} 
bracket one's own beliefs and desires and to temporarily take on or "simulate" the beliefs and desires of someone else. ${ }^{17}$ But more than that-and this is what often makes attempts to understand others so difficult, and perhaps sometimes practically impossible-it apparently involves the ability to unearth the various deeply implicit cultural ideas and assumptions that structure another person's way of looking at the world. These are the elements that the sociologist Harold Garfinkel (1967) has insightfully labeled the "for granteds" - the things that are so part of the cultural air we breathe that we scarcely even notice them.

Flagging the importance of the "for granteds" also make it clear that the act of taking up the perspective of another person will almost certainly require a fairly demanding amount of self-examination. For in order to temporarily bracket not just our own beliefs and desires but also our own "for granteds," we need to be able to unearth the implicit assumptions that we have adopted as part of our culture or upbringing. Far from an easy task, no doubt.

All in all, it is therefore not difficult to sympathize with the great writer Flannery O'Connor's scepticism about the possibility of understanding others, as recorded in one of her letters: "Love and understanding are one and the same only in God. Who do you think you understand? If anybody, you delude yourself. I love a lot of people, but understand none of them" (O'Connor 1988).

But even if we can sympathize with O'Connor's basic doubt, a middle ground seems available here. For instance, it seems fair to say that what O'Connor is talking about here is fully understanding another person-and we can grant that this might be impossible for creatures like us. Yet if we allow, as I believe we should, that understanding comes in degrees, then it seems possible to take up the perspective of others more or less successfully to the extent that we are able-to a greater or lesser degree-to "take on" the beliefs, desires, and for granteds of others, while temporarily bracketing our own.

Undoubtedly part of what makes this so difficult is that most of us lack the sort of character-level intellectual virtues that might help us. To name a few: the temperament to set aside judgmentalism about another person's point of view, the intellectual courage to unearth our own "for granteds," the ability to move beyond our own "egocentric bias" which leads us to assume that others are more or less like us, and the open-mindedness that might allow us to consider the "aspects of the good" under which agents have conceived their action, even when we find those actions repellent or repugnant.

\footnotetext{
${ }^{17}$ Amy Coplan (2011) refers to this "other-oriented perspective taking," and distinguishes it from other mental acts that sometimes go under the name "empathy." She also helpfully reviews the psychological literature on these various mental acts.
} 
In actual fact, then, even partially successful attempts to understand others will be shot through with intellectual character virtues such as open-mindedness, intellectual courage, and intellectual humility. The importance of these virtues will only increase, moreover, the more alien the agent or culture that we are trying to understand. ${ }^{18}$

\footnotetext{
${ }^{18}$ Thanks to Jason Baehr, Sarah Coakley, Chris Cowie, Michel Croce, Kate Elgin, Georgi Gardiner, Emma Gordon, Allan Hazlett, Xingming Hu, Chris Kelp, Kareem Khalifa, Bernhard Salow, Whitney Schwab, Paulina Sliwa, Mona Simion, Yujia Song, and Jay Wood for very helpful comments on earlier versions of this paper.
} 


\section{Works Cited}

Battaly, Heather. 2015. Virtue. Malden, MA: Polity Press.

Baehr, Jason. 2011. The Inquiring Mind: On Intellectual Virtues and Virtue Epistemology. New York: Oxford University Press.

-----. 2014. "Sophia: Theoretical Wisdom and Contemporary Epistemology." In Virtues and Their Vices. Eds. Kevin Timpe and Craig Boyd. New York: Oxford University Press.

----. 2016. “Responsibilist Virtue and the 'Charmed Inner Circle' of Traditional Epistemology." Philosophical Studies.

-----. Forthcoming. "Intellectual Virtues and Truth, Understanding, and Wisdom." In Oxford Handbook of Virtue. Ed. Nancy Snow. New York: Oxford University Press.

Beard, Mary. 2016. "Ultimate Rome: Empire Without Limit: Episode 3." British Broadcasting Company. Original Air Date: May 11, 2016.

Coplan, Amy. 2011. "Understanding Empathy: Its Features and Effects." In Empathy: Philosophical and Psychological Perspectives. Eds. Amy Coplan and Peter Goldie. New York: Oxford University Press.

Elgin, Catherine. 2007. "Understanding and the Facts." Philosophical Studies 132: 33-42.

Garfinkel, Harold. 1967. Studies in Ethnomethodology. Englewood Cliffs, NJ: Prentice Hall.

Greco, John. 2010. Achieving Knowledge. New York: Cambridge University Press.

-----. 2014. "Episteme: Knowledge and Understanding." In Virtues and Their Vices. Eds. Kevin Timpe and Craig Boyd. New York: Oxford University Press.

-----. 2016. "Satisfying Understanding." In Explaining Understanding: New Perspectives from Epistemology and Philosophy of Science. Eds. Stephen R. Grimm, Christoph Baumberger, Sabine Ammon. New York: Routledge. 
Grimm, Stephen R. 2006. "Is Understanding a Species of Knowledge?" British Journal for the Philosophy of Science 57: 515-35.

-----. 2011. "Understanding." In The Routledge Companion to Epistemology. Eds. Duncan Pritchard and Sven Berneker. New York: Routledge.

-----. 2014. "Understanding as Knowledge of Causes." In Virtue Epistemology Naturalized: Bridges Between Virtue Epistemology and Philosophy of Science. Ed. Abrol Fairweather. New York: Springer.

----. 2015. "Wisdom." Australasian Journal of Philosophy 93: 139-54.

----. 2016. "How Understanding People Differs From Understanding the Natural World." Philosophical Issues (A Supplement of Nous) 26: 20925.

----. Forthcoming. "The Ethics of Understanding."

Hills, Alison. 2016. “Understanding Why." Nous 50: 661-88.

Lawler, Insa. 2016. "Reductionism About Understanding Why." Proceedings of the Aristotelian Society 116: 229-36.

Moravscik, Julius. 1979. “Understanding and Knowledge in Plato's Philosophy." Neue Hefte für Philosophe 15: 53-69.

Nagel, Thomas. 1974. "What is it Like to be a Bat?" Philosophical Review 83: 435-50.

O’Brien, Lilian. Forthcoming. "Phenomenal Understanding."

O'Connor, Flannery. 1998. "Letter to XX." In The Habit of Being: Letters of Flannery O'Connor. Ed. Sally Fitzgerald. New York: Farrar, Straus, and Giroux.

Pritchard, Duncan. 2010. "Knowledge and Understanding." In The Nature and Value of Knowledge: Three Investigations. New York: Oxford University Press.

Roberts, Robert, and Jay Wood. 2007. Intellectual Virtue: An Essay in Regulative Epistemology. New York: Oxford University Press.

Riggs, Wayne. 2003. "Understanding Virtue and the Virtue of 
Understanding." In Intellectual Virtue: Perspectives from Ethics and Epistemology. Eds. Michael DePaul and Linda Zagzebski. New York: Oxford University Press.

Simon, Caroline. 1989. "Judgmentalism." Faith and Philosophy 6: 275-87.

Sliwa, Paulina. 2015. "Understanding and Knowing." Proceedings of the Aristotelian Society 115: 57-74.

Sosa, Ernest. 2001. "Human Knowledge, Animal and Reflective." Philosophical Studies 106: 193-96.

----. 2015. Judgment and Agency. New York: Oxford University Press.

-----. Forthcoming. "Firsthand Knowledge and Understanding: Toward an Epistemology for Philosophy and the Humanities."

Stueber, Karsten. 2012. "Understanding Versus Explanation? How to Think About the Distinction Between the Human and the Natural Sciences." Inquiry 55: 17-32.

Woodward, James. 2003. Making Things Happen. New York: Oxford University Press.

Zagzebski, Linda. 1996. Virtues of the Mind: An Inquiry into the Nature of Virtue and the Ethical Foundations of Knowledge. New York: Cambridge University Press.

----. 2011. "Recovering Understanding." In Knowledge, Truth, and Duty: Essays on Justification, Reliability, and Virtue. Eds. M. Steup. New York: Oxford University Press.

-----. Forthcoming. "Towards a Theory of Understanding." 